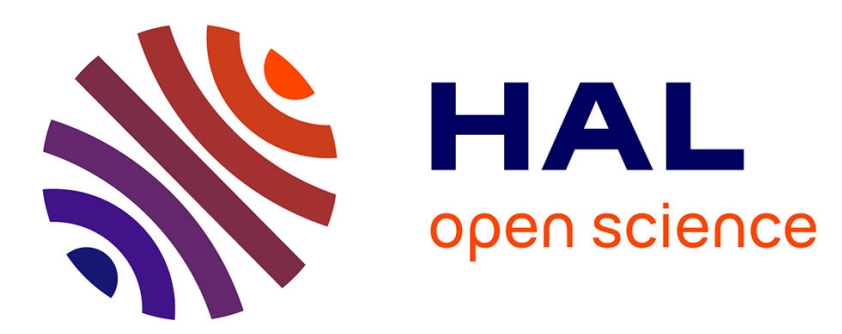

\title{
Effect of intravenous hydration in patients receiving bisphosphonate therapy
}

David Attivi, Gaétan Kosmalski, Claire Zeghmouli, Stéphane Gibaud

\section{To cite this version:}

David Attivi, Gaétan Kosmalski, Claire Zeghmouli, Stéphane Gibaud. Effect of intravenous hydration in patients receiving bisphosphonate therapy. International Journal of Clinical Pharmacy, 2014, 36 (6), pp.1277-1281. 10.1007/s11096-014-9994-x . hal-01169102

\section{HAL Id: hal-01169102 https://hal.science/hal-01169102}

Submitted on 27 Jun 2015

HAL is a multi-disciplinary open access archive for the deposit and dissemination of scientific research documents, whether they are published or not. The documents may come from teaching and research institutions in France or abroad, or from public or private research centers.
L'archive ouverte pluridisciplinaire HAL, est destinée au dépôt et à la diffusion de documents scientifiques de niveau recherche, publiés ou non, émanant des établissements d'enseignement et de recherche français ou étrangers, des laboratoires publics ou privés. 


\section{Effect of intravenous hydration in patients receiving bisphosphonate therapy}

David Attivi ${ }^{1}$, Gaétan Kosmalski ${ }^{1}$, Claire Zeghmouli ${ }^{1}$, Stéphane Gibaud ${ }^{1,2,3}$

1. CHOV, Site de Neufchâteau, Pharmacie, 1280, avenue de la division Leclerc, 88300 Neufchâteau, France.

2. Equipe CITHEFOR (EA3452) - Université de Lorraine - 5, rue Albert Lebrun (Faculté de Pharmacie), 54000 Nancy - France.

3. Pharmacie Clinique - Université de Lorraine - 5, rue Albert Lebrun (Faculté de Pharmacie), 54000 Nancy - France.

Corresponding author: Stéphane Gibaud - Faculté de Pharmacie - 5, rue Albert Lebrun - 54000 Nancy - France

Email: stephane.gibaud@univ-lorraine.fr

Tél: +33 383682306 


\section{Abstract}

Background: Patients with advanced cancers are at high risk for bone metastases, which accelerate bone resorption and skeletal complications. Therefore, bisphosphonates, which are strong inhibitors of bone resorption, are widely used to prevent pathological fractures, pain and tumour-induced hypercalcaemia. Intravenous infusion of bisphosphonate is associated with dose- and infusion ratedependent adverse renal effects.

Objective: The present study investigated the effect of hydration on bisphosphonate efficacy and safety.

Settings: The 600-bed CHOV Hospital (Neufchâteau, France) and the Université de Lorraine (Nancy, France).

Methods: Patients who received pamidronate or zoledronic acid treatments were identified: 50 patients [16 of whom were hydrated and 34 of whom were non-hydrated]. Data on serum calcium levels, creatinine clearance and clinical tolerance were collected.

Main outcome measure: The impact of hydration on these parameters was analysed between day 1 and day 7 .

Results: Bisphosphonate normalized calcaemia and hydration did not induce further reduction of calcium levels. Patient kidneys were significantly preserved by hydration in both groups (median clearance : $+6.2 \%$ ), whereas dehydrated patients had lower creatinine clearance (median calcaemia clearance : - $1.1 \%$ ). Hydration did not influence other clinical or biological parameters tested.

Conclusion: Hydration plays an important role in the treatment of hypercalcaemia by pamidronate and zoledronic acid: it enhances kidney protection (i.e., creatinine clearance).

Keywords: hypercalcaemia; biphosphonate; cancer; side effect; renal toxicity

\section{Impact of findings on practice}

- Hydration enhanced kidney protection during biphosphonate therapy

- If there in no contraindication, hydration should be done for each patient 


\section{Introduction}

Hypercalcaemia is a complication of malignant diseases and has been reported to occur in approximately $20 \%$ to $30 \%$ of patients with malignancies during the course of their disease [1]. If untreated, hypercalcaemia can lead to renal failure, progressive mental impairment and death. In particular, hypercalcaemia causes significant morbidity and mortality in breast cancer patients.

Bisphosphonates are analogues of inorganic pyrophosphates used in the treatment of various osseous diseases such as osteoporosis, multiple myeloma or bone metastasis of solid tumours (with or without hypercalcaemia). Acting as inhibitors of bone resorption, bisphosphonates prevent the loss of bone mass, pain and hypercalcaemia. Bisphosphonates are commonly used in elderly patients, who often present with kidney disease or age-related reductions in the estimated glomerular filtration rate. Although bisphosphonates are generally well tolerated in clinical studies, the low incidence of adverse renal events necessitates the "warnings" described in the prescribing information of all bisphosphonates regarding the use of these drugs in patients with severe chronic kidney disease (creatinine clearance $<30$ or $35 \mathrm{ml} / \mathrm{min}$.).

The U.S. Food and Drug Administration (FDA) safety newsletter reported 35 cases (11 fatal) of renal impairment and acute renal failure associated with the use of $5 \mathrm{mg}$ of zoledronic acid between April 2007 and April 2011[2]. Manufacturers were subsequently required to modify the package insert for all bisphosphonates, stating that it is not recommended for use in patients with severe renal impairment [creatinine clearance $<30 \mathrm{ml} / \mathrm{min}$. (risedronate[3], oral and i.v. ibandronate[4]) or $<$ $35 \mathrm{ml} / \mathrm{min}$. (alendronate[5])], and intravenous zoledronic acid is now only 
recommended for patients with mild to moderate renal impairment and is contraindicated for patients with creatinine clearance $<35 \mathrm{ml} / \mathrm{min}[6]$.

Although intravenous pamidronate is generally well tolerated, six cases of acute kidney injury were reported in patients with multiple myeloma or breast cancer [7]. Tralongo also reported renal function decline in patients in the 12 months following intravenous pamidronate treatment [8]. Additionally, in a controlled study of 22 patients treated with pamidronate versus zoledronic acid, the final serum creatinine levels measured were significantly higher than baseline values $(96.8 \mu \mathrm{mol} / \mathrm{l}$ after treatment, $79.2 \mu \mathrm{mol} / \mathrm{l}$ before treatment, $p=0.01$ ) [9].

Although studies have reported a good tolerance in hypercalcaemic patients, the impact of hydration on bisphosphonates has not been clearly described in the literature. Marketing information emphasises that patients must be adequately hydrated to ensure that they are fully rehydrated prior to the infusion. Moreover, to increase renal excretion of calcium, hypercalcaemia must be treated with serum saline hydration, but caution should be exercised in treated patients with cardiovascular conditions [1, 10]. However, hydration alone is not sufficient to maintain normal calcium levels in cancer patients. Therefore, bisphosphonates must be used as an adjuvant therapy. Few studies have evaluated the impact of intravenous hydration in patients receiving bisphosphonate therapy.

\section{Aim of the study}

The present study aims to determine whether hydration with isotonic saline or glucose affects pamidronate or zoledronic acid treatment efficacy and tolerance. 
Int J Clin Pharm, 2014, DOI : 10.1007/s11096-014-9994-x

\section{Ethical approval}

This study was retrospective. According to French law (consistent with a European directive), an approval from an IRB/IEC [Comité de protection des personnes (CPP) in France] was not necessary. 


\section{Methods}

Study design and setting

We performed a retrospective comparative study in patients receiving treatment with bisphosphonates (CHOV, Lorraine, France). A tender was launched in june 2011 and zoledronic acid was proposed instead of pamidronate. The study was performed in collaboration with the Université de Lorraine (Clinical Pharmacy).

\section{Patients}

Table I. Description of the patient treatment groups.

\begin{tabular}{lcc}
\hline & & \\
\hline Number of patients & Rehydrated & Non-rehydrated \\
$\quad$ Pamidronate & 16 & 34 \\
$\quad$ Zoledronic acid & 9 & 15 \\
Age (years) - median; [range] & 7 & 19 \\
Weight (kg) -median; [range] & $76 ;[62-87]$ & $74 ;[60-93]$ \\
Blood calcium levels on day 1 (mmol/l) - median: [range] & $3.14 ;[2.64-3.67]$ & $73.5[38-131]$ \\
\end{tabular}

Admitted patients (Table I) who were candidates for bisphosphonate infusions between 2008 to 2012 were considered eligible for this study if they were 18 years of age or older, had a primary or advanced cancer diagnosis or benign diseases and had laboratory-diagnosed hypercalcaemia (calcaemia: 2.65 to $3.80 \mathrm{mmol} / \mathrm{L}$ ) at cancer diagnosis or during the treatment period. Patients were considered ineligible for the study if they had used thiazides, diuretics, calcitonin, calcium, hypercalcaemic drugs within the previous 7 days or any sign of dehydration. 


\section{Data collection}

Information for this study was obtained from medical records. The following data were collected: age, weight, type of cancer, volume of hydrate solution, furosemide use, number of bisphosphonate infusions and other information related to the use of these drugs. Information on biological parameters [blood calcium levels, renal clearance (estimated by " Modification of Diet in Renal Disease" MDRD), blood phosphate and magnesium levels] was collected at the onset of bisphosphonate treatment and on day 7. Safety was evaluated according to the incidence and severity of adverse events, and the relationship of the adverse events to the treatment was determined based on patient reports. Tolerance data were collected on day 1 and day 7 .

Statistical analysis

Data analysis was performed with statistical software (Kaleidagraph 4.1. Synergy Software). The Mann-Whitney test was used to assess statistical significance. $p$ values less than or equal to 0.05 were considered significant. 


\section{Results}

\section{Patient characteristics}

A total of 50 patients were candidates for and received treatment during the study period. Among them, 24 patients received pamidronate (78 $\mathrm{mg} \pm 15 \mathrm{mg}$ every 4 weeks) and 26 patients received zoledronic acid (3.8 $\mathrm{mg} \pm 0.5 \mathrm{mg}$ every 4 weeks). In the pamidronate group, 9 patients received normal saline solution. In the zoledronic acid group, 7 patients received normal saline solution. Among the 50 patients, 46 were treated for cancers (92\%), 2 were treated for hyperparathyroidism (4\%) and 2 were treated for osteoporosis and sarcoidosis (5\%). Fourteen patients had lung cancer, 11 had breast cancer, 5 had colorectal cancer and 4 had prostatic cancer. The median age and weight at first hospitalisation for the cancer patients were 75.6 years and $68 \mathrm{~kg}$, respectively.

Impact of hydration on bisphosphonates efficacy and renal toxicity

The fifty patients in the study received more than 2 years of pamidronate or zoledronic acid infusion. A total of 16 patients (32\%) received hydration before bisphosphonate therapy. The hydration was done just before the administration of bisphosphonate with isotonic saline solution or glucose, and the mean volume used was $30 \pm 5 \mathrm{ml} / \mathrm{kg} /$ day (about $2000 \mathrm{ml}$ for $66 \mathrm{~kg}$ ). The infusion was maintained for $24 \mathrm{~h}$. Thirteen patients received furosemide $(40$ to $80 \mathrm{mg}$ ) during hydration. 
Both treatments (i.e. with or without hydration) allow a normalization of the median value of calcaemia and only 9 patients were hypocalcaemic after 7 days (i.e. $<2.2$ $\mathrm{mmol} / \mathrm{L})$. In the hydrated patients group, the median calcium value decreased from $3.14 \mathrm{mmol} / \mathrm{l}$ to $2.36 \mathrm{mmol} / \mathrm{l}(-25 \%)$. In the non-hydrated patients group, the median calcium value decreased from $3.00 \mathrm{mmol} / \mathrm{l}$ to $2.23 \mathrm{mmol} / \mathrm{l}(-26 \%)$. Variations between day 1 and day 7 were also determined for each patient and the results for each group are shown in figure 1.

Hydration usually does not induce hypocalcaemia and, in our study, it did not induce further reduction of the calcaemia level (Figure 1, $p=0.388$ ).

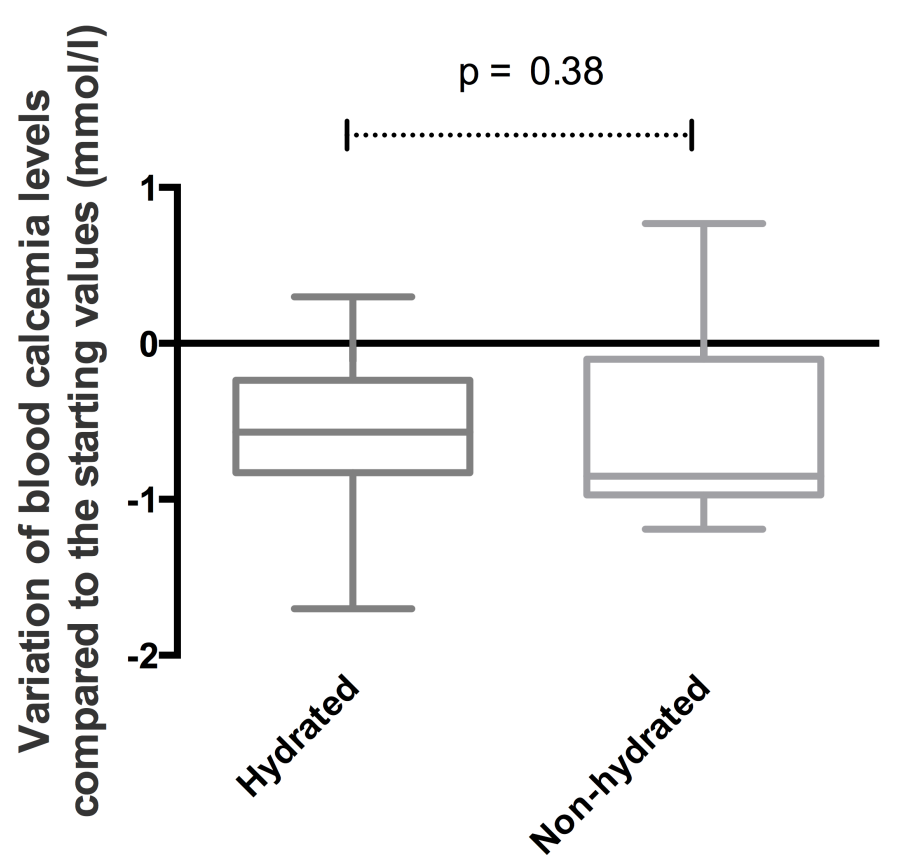

Figure 1. Variations in blood calcium levels compared to the starting values (Day 7 - Day 1 ) for each treatment group. Medians value, top and bottom box edges denote the first and third quartile. Whiskers denote the largest and smallest data within 1.5 times the interquartile range. 
In addition to calcium levels, renal function was evaluated on day 1 and day 7 . Among hydrated patients, we observed a significant improvement in creatinine clearance compared to the patients in the non-hydrated treatment group (Figure 2, $p<0.05)$. In the hydrated patients group, the median clearance value increased from $65 \mathrm{ml} / \mathrm{min}$ to $69 \mathrm{ml} / \mathrm{min}(+6.2 \%)$. In the non-hydrated patients group, the median clearance value decreased from $89 \mathrm{ml} / \mathrm{min}$ to $88 \mathrm{ml} / \mathrm{min}(-1.1 \%)$.

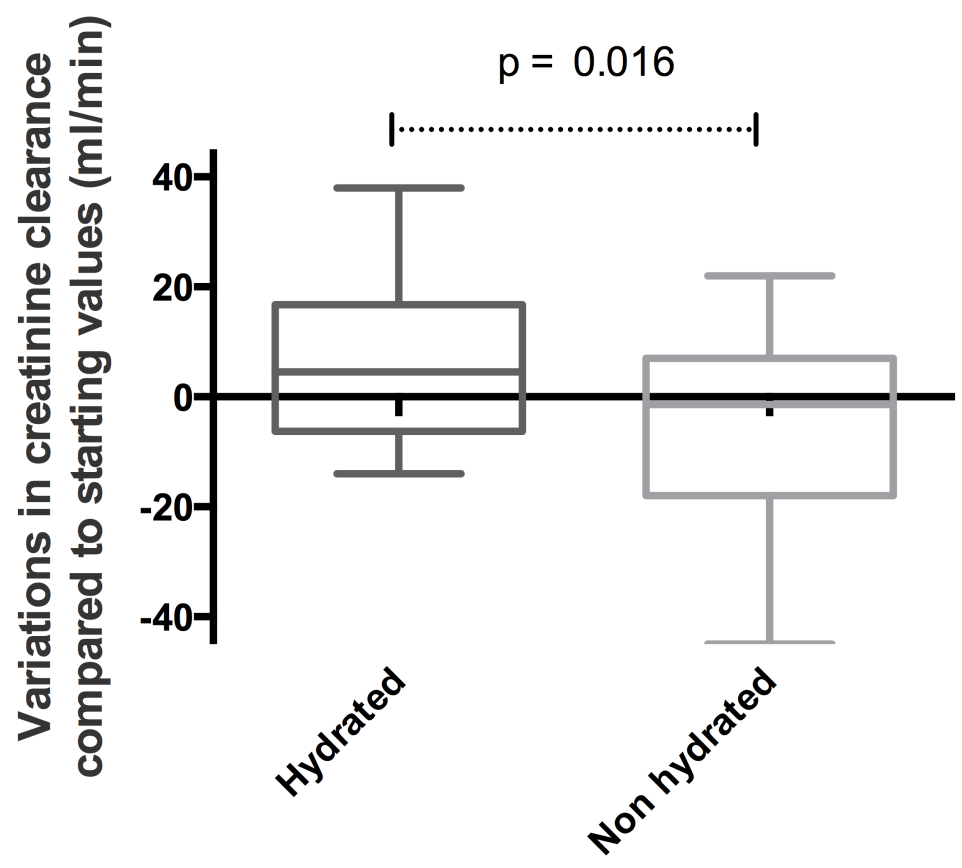

Figure 2. Variations of creatinine clearance compared to the starting values (Day 7 - Day 1 ) for each group. Medians value, top and bottom box edges denote the first and third quartile. Whiskers denote the largest and smallest data within 1.5 times the interquartile range.

Impact of hydration on clinical tolerance and biology

We evaluated the importance of hydration on clinical tolerance of bisphosphonates. We focused our evaluation on the adverse effects of bisphosphonates that are 
frequently reported in the literature. During the first 2 years of treatment, 1 patient developed flu-like symptoms hydrated treatment group. Among the non-hydrated groups, one case of flu-like symptoms was also observed. Myalgia and eye disorders occurred in 4 patients in the non-hydrated treatment groups. There was no osteonecrosis of the jaw in either group, and there were no clinically important changes in blood cell counts or electrolyte analysis for the patients receiving longterm therapy. Treatment was stopped in both groups due to systemic disease progression and death.

\section{Discussion}

Zoledronic acid and pamidronate have been marketed for the past 10 years for the treatment of hypercalcaemia in patients with multiple myeloma or a broad range of solid tumours. The safety profile of zoledronic acid and pamidronate was well established from the databases of several large randomised trials and post marketing clinical experience. Although the manufacturers recommend hydration, its implication on the efficacy and safety of bisphosphonates has not been clearly reported in literature.

Hydration in itself is a key factor in the management of hypercalcaemia and its association with loop diuretics is usually recommended but it does not consistently normalize calcium levels quickly, even at markedly higher doses than those routinely prescribed [11]. The general recommendation for hydration, if necessary, with at least $2 \mathrm{~L}$ of saline solution intravenously for $24 \mathrm{~h}$ as the first line treatment of hypercalcaemia is usually not exhaustively followed in all patients [12]. In theory, 
hydration should accelerate calcium removal and protect renal function and the decrease of calcium levels is know to be about $0.5 \mathrm{mmol} / \mathrm{L}$.

In our study, bisphosphonate were sufficient to normalize the calcium levels and hydration did not play a key role for further reduction of calcium levels.

Bisphosphonates are not metabolised. In fact, between $27 \%$ and $62 \%$ of the drug binds to bone mineral, and the rest is excreted via the kidneys, primarily within hours after administration [13, 14]. When bisphosphonates were first being used, Bounameaux reported three cases of renal toxicity in humans following IV administration [15]. The formation of aggregates within the blood, toxic acute tubular necrosis, tubulointerstitial damage and focal segmental glomerulosclerosis have been reported as toxicological mechanisms [16-20]. As indicated by our results, hydration considerably improved renal safety by enhancing renal clearance between day 1 and day 7 in both treatment groups. Among patients who did not receive hydration, we observed a significant reduction in renal clearance. Considering that the patients included in our study were elderly, hydration appears to be important for preventing the occurrence of acute kidney injury. Our study suggests that hydration with at least $30 \pm 5 \mathrm{ml} / \mathrm{kg} /$ day of IV saline solution prior to drug exposure is consistently beneficial. It is known that, in a dehydrated state, the renal blood flow and glomerular filtration rates decrease, which can impact the toxic effect of drugs. This finding was reported mainly with radiographic contrast media. Hydration with saline for 12 hours before and 12 hours after the administration of radiocontrast agents has been found to be the most effective means of preventing acute decreases in renal function in patients with chronic renal insufficiency with or without diabetes mellitus [21]. Thus, it can be argued that hydration both counteracted the prolonged 
tubular exposure to drug-induced nephrotoxicity when the tubular flow rates were lowered and controlled stimulation of the renin-angiotensin system.

Although no rigorously controlled randomised trial with sufficient statistical power has been performed to verify the benefit of hydration, it is almost universally accepted as an appropriate and safe measure to prevent kidney injury. Caution must be taken with patients suffering from heart failure or those who may be insufficiently hydrated due to other conditions or a higher degree of renal insufficiency.

\section{Conclusion}

In our study, we found that hydration plays an important role in the treatment of hypercalcaemia with pamidronate and zoledronic acid. Hydration enhanced kidney protection (i.e., clearance). This study was an opportunity in our hospital. Now we advise to make a hydration for each patient and therefore it is not possible to increase the number of patient. Hydration did not have a significant impact on other bisphosphonate side effects.

Acknowledgements We thank all physicians and nurses who helped us for this study.

Funding : None.

Conflicts of interest : None 


\section{References}

[1] Stewart A. Hypercalcemia associated with cancer. N Engl J Med. 2005; 352: 373-79.

[2] U.S. Food and Drug Administration. Zoledronic acid for osteoporosis (marketed as reclast). In: FDA (ed)). Drug Safety Newsletter - vol2(2). Silver Spring: FDA, 2009; 16-18.

[3] Actonel® - Prescribing information. 2013.

http://www.actonel.com/global/prescribing_information.pdf. Accessed 10 April 2014.

[4] Boniva® - Prescribing information. 2010.

http://www.accessdata.fda.gov/drugsatfda docs/label/2010/021455s009lbl.pdf. Accessed 10 April 2014.

[5] Fosamax® - Prescribing information. 2013.

http://www.merck.com/product/usa/pi circulars/f/fosamax/fosamax pi.pdf. Accessed 10 April 2014.

[6] Reclast ${ }^{\circledR}$ - Prescribing information. 2013.

http://www.pharma.us.novartis.com/product/pi/pdf/reclast.pdf. Accessed 10 April 2014.

[7] Markowitz GS, Appel GB, Fine PL, Fenves AZ, Loon NR, Jagannath S, et al. Collapsing focal segmental glomerulosclerosis following treatment with high dose pamidronate. J Am Soc Nephrol. 2001; 12: 1164-72.

[8] Tralongo P, Repetto L, Di Mari A, Mauceri G, Bollina R, Ferrau F, et al. Safety of long-term administration of bisphosphonates in elderly cancer patients. Oncology. 2004; 67: 112-6.

[9] Ali SM, Esteva FJ, Hortobagyi G, Harvey H, Seaman J, Knight R, et al. Safety and efficacy of bisphosphonates beyond 24 months in cancer patients. J Clin Oncol. 2001; 19: 3434-7.

[10] Lumachi F, Brunello A, Roma A, Basso U. Cancer-induced hypercalcemia. Anticancer Res. 2009; 29: 1551-5.

[11] LeGrand SB. Narrative Review: Furosemide for Hypercalcemia: An Unproven yet Common Practice. Ann Intern Med. 2008; 149: 259-63.

[12] Fisken RA, Heath DA, Bold AM. Hypercalcaemia--a hospital survey. QJM-Int J Med. 1980; 49: 405-18.

[13] Russell RG, Watts NB, Ebetino FH, Rogers MJ. Mechanisms of action of bisphosphonates: similarities and differences and their potential influence on clinical efficacy. Osteoporos Int. 2008; 19: 733-59.

[14] Luhe A, Kunkele KP, Haiker M, Schad K, Zihlmann C, Bauss F, et al. Preclinical evidence for nitrogen-containing bisphosphonate inhibition of farnesyl diphosphate (FPP) synthase in the kidney: implications for renal safety. Toxicol In Vitro. 2008; 22: 899-909.

[15] Bounameaux HM, Schifferli J, Montani JP, Jung A, Chatelanat F. Renal failure associated with intravenous diphosphonates. Lancet. 1983; 1: 471.

[16] Fleisch H. Bisphosphonates: mechanisms of action. Endocr Rev. 1998; 19: 80-100.

[17] Green JR, Seltenmeyer Y, Jaeggi KA, Widler L. Renal tolerability profile of novel, potent bisphosphonates in two short-term rat models. Pharmacol Toxicol. 1997; 80: 225-30.

[18] Markowitz GS, Fine PL, Stack JI, Kunis CL, Radhakrishnan J, Palecki W, et al. Toxic acute tubular necrosis following treatment with zoledronate (Zometa). Kidney Int. 2003; 64: 281-9. 
[19] Bodmer M, Amico P, Mihatsch MJ, Haschke M, Kummer O, Krahenbuhl S, et al. Focal segmental glomerulosclerosis associated with long-term treatment with zoledronate in a myeloma patient. Nephrol Dial Transplant. 2007; 22: 2366-70.

[20] Henley D, Kaye J, Walsh J, Cull G. Symptomatic hypocalcaemia and renal impairment associated with bisphosphonate treatment in patients with multiple myeloma. Intern Med J. 2005; 35 : 726-8.

[21] Solomon R, Werner C, Mann D, D'Elia J, Silva P. Effects of saline, mannitol, and furosemide to prevent acute decreases in renal function induced by radiocontrast agents. N Engl J Med. 1994; 331: 1416-20. 